\title{
Pênfigo foliáceo canino: estudo retrospectivo de 43 casos clínicos e terapia $(2000-2005)^{1}$
}

\author{
Ana C. Balda ${ }^{2 *}$, Mary O. Ikeda ${ }^{3}$, Carlos E. Larsson Junior ${ }^{3}$, Nílceo S. \\ Michalany ${ }^{4}$ e Carlos E. Larsson ${ }^{5}$
}

\begin{abstract}
Balda A.C., Ikeda M.O., Larsson Junior C.E., Michalany N.S. \& Larsson C.E. 2008. [Canine Pemphigus foliaceus: A retrospective study of 43 clinical cases and therapy (2000-2005).] Pênfigo foliáceo canino: estudo retrospectivo de 43 casos clínicos e terapia (2000-2005). Pesquisa Veterinária Brasileira 28(8):387-392. Departamento de Clínica Médica, Faculdade de Medicina Veterinária e Zootecnia, Universidade de São Paulo, Av. Prof. Dr. Orlando Marques de Paiva 87, São Paulo, SP 05508-270. Brazil. E-mail: anabalda@terra.com.br

From August 2000 to July 2005 were attended 43 cases of canine Pemphigus foliaceous (PF) by the Dermatology Service of the Veterinary Teaching Hospital, University of São Paulo. The aim of the present study was to update the records referred to sex, breed, age, type and location of the lesions, clinical signs, and response to treatments with prednisone or combination with prednisone and azathioprine, and also to demonstrate the increase of occurrence of PF compared with the former series (1986-2000) observed in the same Service.
\end{abstract}

INDEX TERMS: Pemphigus foliaceous; dogs, therapy.

RESUMO.- No período de agosto de 2000 a julho de 2005 foram atendidos 43 casos de Pênfigo Foliáceo (PF) canino no Serviço de Dermatologia do Hospital Veterinária, Universidade de São Paulo. Com este estudo retrospectivo visou-se atualizar dados referentes à caracterização sexual, definição racial e raça, idade, tipo e topografia lesional, quadro sintomático e resposta aos tratamentos isolados com prednisona e com a associação desta à azatioprina, além de demonstrar o aumento na ocorrência do PF relativamente à série histórica pretérita (19862000) do mesmo Serviço.

TERMOS DE INDEXAÇÃO: Pênfigo foliáceo, cães, terapia.

\footnotetext{
${ }^{1}$ Recebido em 20 de outubro de 2007.

Aceito para publicação em 19 de agosto de 2008

2 Doutoranda do Departamento de Clínica Médica, Faculdade de Medicina Veterinária e Zootecnia (FMVZ), Universidade de São Paulo (USP), Cidade Universitária. Endereço particular: Rua Carlos Weber 633, Apto 134A, São Paulo, SP 05303-000, Brasil. *Autor para correspondência: anabalda@terra.com.br

${ }^{3}$ Serviço de Dermatologia do Hospital Veterinário (HOVET), FMVZ-USP, Av. Prof. Dr. Orlando Marques de Paiva 87, São Paulo, SP 05508-270.

${ }^{4}$ Departamento de Patologia, Universidade Federal de São Paulo (Unifesp), Av. Brigadeiro Luís Antônio 4315, São Paulo, SP 01402-971.

${ }^{5}$ Departamento de Clínica Médica de Pequenos Animais, FMVZ-USP, São Paulo, SP.
}

\section{INTRODUÇÃO}

O Pênfigo foliáceo (PF), classicamente denominado de Doença de Cazenave, constitui-se em doença de etiologia auto-imune, sendo considerada a forma mais comum das doenças do Complexo Pênfigo. Sabe-se que as dermatopatias auto-imunes correspondem a $1,0-1,5 \%$ da casuística de atendimento dos serviços de referência em dermatologia. (Scott et al. 2001). Muitos autores acreditam que o PF é dermatopatia auto-imune mais freqüentemente observada em cães e gatos, ficando aquém ou muito próximo, em termos de ocorrência, à casuística de Lúpus eritematoso (Scott 1987). O PF canino foi descrito, pela primeira vez, na década de setenta nos EUA, mais precisamente em 1977 por Halliwell \& Goldshmidt (1977). O termo Pênfigo, inicialmente foi utilizado na medicina humana para denominar as doenças vesico-bolhosas. Etimologicamente tem origem grega onde pemphis, pompholix significa bolha, e o termo foliaceus decorre da severa descamação, que se assemelha a folhas, e que consiste em manifestação clínica comumente observada (Ihrke et al. 1985). Apesar de a doença canina guardar similiaridades com a doença na espécie humana, na espécie canina ele se caracteriza por aspecto de dermatite pustular, que não se desenvolve a partir de lesões eritêmato-vesiculares tal qual é descrito no homem (Scott 
et al. 2001). Somente a variante vulgar inicia-se como vesículas ou bolhas intraepidérmicas e, caracteristicamente, suas lesões se localizam em mucosas e junções mucocutâneas.

Com relação à fisiopatogenia das doenças auto-imunes, sabe-se que os anticorpos ou linfócitos ativados são dirigidos contra células do próprio organismo. No PF sabese que o principal antígeno envolvido é a desmogleína I, glicoproteína de $150 \mathrm{Kd}$, do grupo das caderinas, que compõem as moléculas de adesão. Após a ligação dos auto-anticorpos com os antígenos do Pênfigo, há a internalização e fusão com lisossomos intracelulares. Este evento resulta na liberação e ativação do fator de ativação (uroquinase) do plasminogênio que converterá plasminogênio em plasmina. A plasmina é a responsável pela hidrólise das moléculas de adesão intercelular, resultando na perda da coesão entre os queratinócitos (fenômeno denominado de acantólise) e, conseqüentemente, à formação de lacunas intraepidérmicas. No PF, a acantólise ocorre nas camadas mais superficiais da epiderme, fato este que explica a fragilidade das vésicobolhas que facilmente são rompidas levando a formação de lesões crostosas. Já o mecanismo eligiador da anticorpogênese não está totalmente elucidado. A predisposição genética parece ser fator importante no desenvolvimento da auto-imunidade, fato este que explicaria a maior incidência em determinadas raças. Outros fatores são arrolados, dentre estes se têm: infecções virais, medicamentos, imunógenos e condições inflamatórias de decurso crônico principalmente as dermatopatias alérgicas. Citam-se na literatura alguns medicamentos mais comumente envolvidos como a fenilbutazona e penicilamina no desencadeamento do PF canino (Larsson et al. 1998).

Epidemiologicamente, não há aparente predisposição sexual em cães. Afirma-se, no entanto, que a maioria dos casos inicia-se ao redor do quarto ano de idade e que $65 \%$ dos casos se manifestam no primeiro qüinqüênio de vida (Ihrke et al. 1985, Larsson et al. 1998, Gomez et al. 2004).

Segundo Scott et al. (2001) parecem existir três formas de PF canino. A primeira delas seria o PF espontâneo, freqüente em cães da raça Chow Chow e Akita. A segunda forma seria o PF mediado por drogas, dentre elas as sulfas potencializadas e, a terceira forma, seria o PF evidenciado em cães com histórico pretérito de dermatopatias crônicas. Esses cães parecem evoluir por anos com algum dos tipos de dermatopatia alérgica e, inopinadamente, manifestariam uma brusca mudança do quadro lesional, diagnosticado, subseqüentemente, como PF. Tais pacientes também são mais expostos a medicamentos e, portanto tal desencadeamento pode ser igualmente, estimulado por drogas. Alguns autores que a maior ocorrência do PF canino em comparação ao PF humano pode ocorrer por estímulo imunológico através de utilização excessiva de vacinas ou por estimulação intensa de superantígenos bacterianos (Werner 1999).
Clinicamente os cães, com diagnóstico estabelecido de PF, apresentam lesões pustulares, que são bastante efêmeras devido a menor espessura da epiderme canina, quando comparada àquela do homem. Conseqüentemente torna-se muito mais freqüente a observação de lesões secundárias quase sempre representadas por lesões pápulo-crostosas e em colarinho epidérmico decorrente da ruptura pustular.

Topograficamente, as lesões assestam-se, de início, na face e pavilhões auriculares e, freqüentemente, envolvem os coxins palmo-plantares, os membros, a região abdominal ventral e em cerca de $60 \%$ dos animais, tornam-se multifocais ou generalizadas dentro de seis meses. Também, pode ocorrer comprometimento ungueal. O envolvimento de mucosas e junções mucocutânea é bastante raro. Afora o prurido, a dor e as infecções bacterianas secundárias não são, insolitamente, freqüentes (Scott et al. 2001, Gomez et al. 2004, Mueller et al. 2006). Manifestações sistêmicas, a exemplo de pirexia, depressão, claudicação, edema, linfoadenopatia e leucocitose neutrofílica podem ocorrer, nas formas graves e generalizadas (Larsson et al. 1998).

O diagnóstico baseia-se nos dados de anamnese, nos aspectos sintomáticos e nas lesões tegumentares (tipos e localização) além da freqüente evidenciação de células acantolíticas, pela Técnica de Tzanck, em material colhido de conteúdo pustular. Tais células acantolíticas são células da camada espinhosa que perderam suas pontes de adesão e se encontram soltas nas lacunas da epiderme. Como exame complementar soberano, indica-se o histopatológico. Neste, confirma-se o diagnóstico através da evidenciação de acantólise subcorneal ou intragranulosa, que resulta na formação de fendas que são clinicamente retratadas pelo surgimento de lesões pustulares e, também, pela presença de acantócitos. Os métodos de imunofluorescência direta e indireta e imunoistoquímica são também exames complementares para o diagnóstico, porém são pouco empregados, na dermatologia veterinária, face ao custo e à técnica trabalhosa. Na Imunofluorescência direta de lesões observa-se a deposição epidérmica intercelular de $\operatorname{lgG}$ e/ou complemento. A Imunofluorescência indireta pesquisa a presença de auto-anticorpos diretamente voltados à substância cementante. Segundo Scott (1989) resultados das reações de imunofluorescência em cães com PF é geralmente negativo, mas outros autores (Nishifuji et al. 2005) sugerem que titulações seqüenciais de anticorpos séricos podem ser úteis na monitoração da atividade do PF canino.

O prognóstico do PF oscila entre reservado e bom. Em muitos pacientes caninos o diagnóstico precoce e preciso, redunda em excelente controle. Infecções secundárias por bactérias são incomuns e, quando presentes, devem ser tratadas com antibióticos apropriados como a cefalexina, a enrofloxacina e a amoxacilina associada ao clavulanato. Alguns cães penfigosos desenvolvem infecções profundas e necessitam de antibioticoterapia por lon- 
gos períodos principalmente devido à utilização de terapia imunossupressora (Gomez et al. 2004).

O fulcro principal da terapia, nos diferentes tipos de PF, é o de minimizá-lo. Preconiza-se o mesmo esquema de tratamento nos três tipos de PF. É observado que no PF induzido por drogas, a remissão é total e permanente e sucede a interrupção da noxa, diferentemente do que ocorre nos demais tipos (Werner 1999). A terapia ortodoxa de eleição para as doenças cutâneas auto-imunes é a utilização dos glicocorticóides sistêmicos em doses imunossupressoras. Tem-se observado muitas vezes que a terapia isolada com glicocorticóides não gera a remissão ansiada. Nestes casos, necessita-se de terapia heterodoxa através da associação de glicocorticóides com drogas citostáticas e em especial a azatioprina. Através desta associação, observa-se a potencialização dos efeitos antiinflamatórios e imunossupressores dos glicorcorticóides, além da redução da dose. Desta maneira, reduz-se, significativamente, os possíveis efeitos adversos.

Scott et al. (2001), afirmaram que os glicocorticóides só se mostravam efetivos em $50 \%$ dos pacientes caninos penfigosos tratados. De acordo com outros autores, dentre os cães penfigosos, apenas $20-40 \%$ respondem bem ao uso isolado dos corticóides (Ihrke et al. 1985, White 2000, Mueller et al. 2006). Na bibliografia nacional, há apenas dois trabalhos publicados enfocando a ineficácia dos glicocorticóides utilizados de forma isolada em cães com PF. Nascimento et al. 2000 relataram a ausência de resposta de um cão penfigoso aos glicocorticóides, levando ao emprego da associação de tetraciclina e niacinamida, que resultou em melhora do quadro. Balda et al. (2002), descreveram a ineficácia dos glicocorticóides em apenas $16,6 \%$ dos 30 pacientes atendidos no HOVET da FMVZ-USP, entre novembro de 1989 a julho de 2000.

Naqueles casos refratários à terapia ortodoxa, recomenda-se, eletivamente, a associação da azatioprina ao esteróide. A dosagem preconizada é de 1,5-2,5m $/ \mathrm{kg} /$ diariamente, de ambas as drogas, per os, durante 4-6 semanas e, então, sugere-se o esquema de redução gradual das medicações. Também, é recomendado o espaçamento posológico para o esquema de dias alternados após a melhora clínico-lesional. Sabe-se que a azatioprina isoladamente não possui a propriedade de eliciar a remissão lesional e que reserva efeito de latência de aproximadamente 15 dias, mesmo quando em associação com glicocorticóides. Olivry et al. (2004) consideraram que pode ocorrer remissão prolongada do quadro de PF após a suspensão da terapia imunossupressora em alguns poucos animais com PF.

Além da azatioprina existem citações de emprego de outras medicações, que poderiam ser úteis na terapia do PF, como: clorambucil, ciclosporina, tacrolimus, micofenato de mofetil, ciclofosfamida crisoterapia, dapsona, sulfasalazina e mesmo a terapia intravenosa com imunoglobulinas (Rosenkrantz 2004).

Em face aos poucos relatos existentes na bibliografia nacional e com o objetivo de atualizar e cotejar dados referentes à publicação pretérita, realizada por Balda et al. (2002), reuniu-se 43 casos caninos com diagnóstico estabelecido de PF, atendidos no Serviço de Dermatologia (SD) do HOVET da FMVZ-USP no período de agosto de 2000 a julho de 2005 (60 meses). Tais pacientes penfigosos foram analisados quanto à definição racial e raça, idade, sexo, tipo e topografia lesional, idade do surgimento lesional, presença de prurido e, ainda, quanto a reposta à terapia com glicocorticóides ou com do uso destes em associação à azatioprina.

\section{MATERIAL E MÉTODOS}

Todos os animais inclusos neste trabalho foram atendidos no SD do HOVET da FMVZ-USP, no período de agosto de 2000 a julho de 2005. Tal amostragem adveio de levantamento retrospectivo dos casos atendidos no Serviço. Procedeu-se a coleta de dados de identificação e anamnese, e dos resultados dos exames físico e dermatológico. O diagnóstico de PF havia sido confirmado pelos resultados de exame histopatológico de lesões biopsiadas e de exame citológico do conteúdo pustular. Os dados coligidos forneceram informações importantes quanto à ocorrência da doença e sua relação com as predisposições sexual, etária, de definição racial e raça, presença de prurido, tempo de evolução e histórico de presença de dermatopatia pretérita. A manifestação de prurido foi graduada em quatro intensidades distintas a partir de pontuações referentes a uma escala de 0 a 10. Tal pontuação era inferida pelo proprietário durante a anamnese. Pelos exames físico e dermatológico, caracterizaram-se os tipos lesionais primitivos e secundários bem como suas localizações.

Segundo o levantamento, uma vez confirmado o diagnóstico de PF, foram submetidos à terapia clássica, per os com prednisona em dose imunossupressora (1-2mg/kg/diariamente) até eventual melhora do quadro lesional (3-4 semanas) e então inicava-se a redução gradual do esteróide, tentando-se sempre obter a mantença da melhora com a menor dose e o maior intervalo posológico possível. Naqueles casos, onde a melhora com a prednisona não era alcançada, iniciava-se a sua associação com a azatioprina, per os, na dose de 1,5-2,5mg/ $\mathrm{kg} /$ diariamente (terapia heterodoxa). Após a melhora sintômatolesional, com a utilização da combinação prednisona e azatioprina, iniciava-se o esquema de redução gradual e aumento no intervalo posológico, tentando-se, inicialmente, medicar os pacientes de forma intercalada com a prednisona e a azatioprina e então procedia-se a redução na dose.

Todos os animais haviam sido submetidos ao seguimento clínico com exames subsidiários (hemograma, contagem de plaquetas, funções renal e hepática e exame de urina) em intervalos de aproximadamente três semanas. Quando do início da interposição da azatioprina, os pacientes eram inclusive avaliados quinzenalmente com a execução de hemogramas completos.

\section{RESULTADOS}

Foram atendidos no período de um qüinqüênio (60 meses), qual seja, de agosto de 2000 a julho de 2005, 43 casos confirmados, por exame histopatológico, de PF. Destes animais, 19 (44,2\%) eram machos e de 24 (55,8\%) remanescentes eram fêmeas. Quanto à definição racial, $10(23,2 \%)$ deles eram de raça indefinida enquanto que $33(76,7 \%)$ apresentavam evidente definição racial, con- 
forme dados dispostos no Quadro 1. Dos pacientes de raça definida, aqueles mais acometidos foram: Cocker Spaniel (9-27,3\%), Dachshund (4-12,1\%), Poodle (4-2,1\%) e Akita (3-9,1\%). Os 13 (39,4\%) cães restantes pertenciam a nove raças distintas. Com relação à idade, no momento do diagnóstico de PF, $23(53,5 \%)$ cães tinham 4-9 anos, $15(35,0 \%)$ de $1-3$ anos, dois $(4,6 \%)$ cães estavam acima dos 9 anos e, finalmente, três $(6,9 \%)$ cães apresentavam menos de 1 ano de idade.

Quadro 1. Ocorrência de Pênfigo Foliáceo em cães segundo definição racial e a raça. Serviço de Dermatologia HOVET, FMVZ-USP (Agosto de 2000 a julho de 2005)

\begin{tabular}{lcc}
\hline Definição racial/Raça & № & $\%$ \\
\hline SRD & 10 & 23,3 \\
CRD & 33 & 76,7 \\
Cocker Spaniel & 9 & 27,3 \\
Dachshund & 4 & 12,1 \\
Poodle & 4 & 12,1 \\
Akita & 3 & 9,1 \\
Lhasa Apso & 2 & 6,0 \\
Pinscher & 2 & 6,0 \\
Boxer & 2 & 6,0 \\
Pitbull & 2 & 6,0 \\
Setter Irlandês & 1 & 3,0 \\
Schnauzer & 1 & 3,0 \\
Dogge Alemão & 1 & 3,0 \\
Dogo Argentino & 1 & 3,0 \\
Fox Terrier & 1 & 3,0 \\
Total & 43 & 100,0
\end{tabular}

Quadro 2. Caracterização lesional em 43 cães com Pênfigo foliáceo, atendidos no Serviço de Dermatologia HOVET, FMVZ/USP (Agosto de 2000 a julho de 2005)

\begin{tabular}{lcc}
\hline \multicolumn{1}{c}{ Lesões elementares } & № animais & $\%$ \\
\hline Crosta hemo-melicérica & 43 & 100,0 \\
Pústulas & 40 & 93,0 \\
Pápulas & 33 & 76,7 \\
Escamas & 29 & 67,4 \\
Alopecia & 27 & 62,8 \\
Eritema & 27 & 62,8 \\
Colarinhos epidérmicos & 27 & 62,8 \\
Hiperqueratose & 15 & 34,9 \\
Hiperpigmentação & 14 & 32,5 \\
Hipopigmentação & 2 & 4,6
\end{tabular}

Quadro 3. Distribuição lesional dos 43 cães com diagnostico de Pênfigo Foliáceo, atendidos no Serviço de Dermatologia HOVET, FMVZ-USP ( Agosto de 2000 a julho de 2005)

\begin{tabular}{lcc}
\hline \multicolumn{1}{c}{ Localização } & № de animais & $\%$ \\
\hline Região dorsal & 41 & 95,3 \\
Região abdominal ventral & 40 & 93,0 \\
Região axilar & 36 & 83,7 \\
Membros & 32 & 74,4 \\
Região cervical & 30 & 69,7 \\
Região coccígea & 29 & 67,4 \\
Pavilhão auricular & 24 & 55,8 \\
Região periocular & 20 & 46,5 \\
Ponte nasal & 19 & 44,2 \\
Coxins & 18 & 41,8 \\
Bolsa escrotal & 9 & 20,9
\end{tabular}

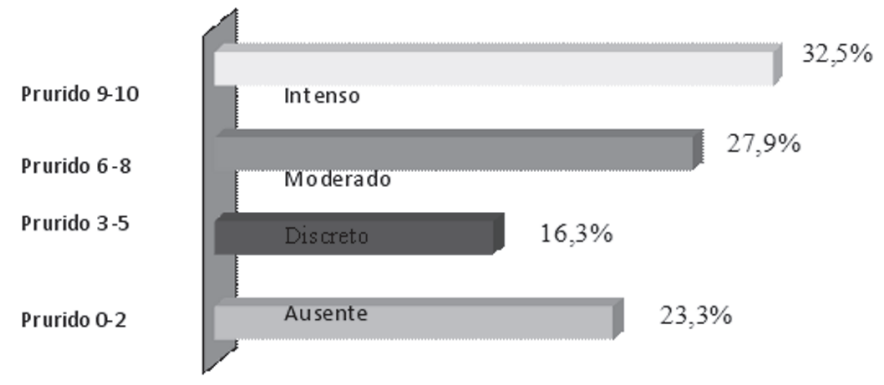

Fig.1. Ocorrência de prurido em cães com Pênfigo foliáceo. Serviço de Dermatologia HOVET/FMVZ-USP (Agosto de 2000 a julho de 2005).

Com referência ao padrão lesional, as lesões mais comumente observadas (Quadro 2) nos 43 cães penfigosos foram: crosta hemo-melicérica $(100 \%)$, pústulas (93,0\%), pápulas $(76,7 \%)$, escamas $(67,4 \%)$, alopecia $(62,8 \%)$, eritema $(62,8 \%)$, lesões em colarinho epidérmico $(62,8 \%)$, hiperqueratose $(34,8 \%)$, hiperpigmentação (32,5\%), hipopigmentação $(4,6 \%)$.

A generalização lesional foi evidenciada em 39 (90,7\%) dos casos, em período de um a seis meses de decurso evolutivo. As lesões acometiam mais freqüentemente (Quadro 3) as regiões: dorsal (95,3\%), abdominal ventral $(93 \%)$, axilar $(83,7 \%)$, de membros $(74,4 \%)$, cervical $(69,7 \%)$ e coccígea $(67,4 \%)$; de pavilhões auriculares $(55,8 \%)$; região periocular (46,5\%); ponte nasal $(44,2 \%)$, coxins palmo-plantares $(41,2 \%)$ e bolsa escrotal $(21,0 \%)$.

O prurido foi considerado ausente nas graduações (02) em $10(23,2 \%)$ animais, classificado como discreto (3-5) em 7 (16,3\%) cães, como moderado (6-8) em 12 (27,9\%) cães e intenso (9-10) em 14 (32,5\%) animais (Fig.1).

Dos 43 pacientes penfigosos, $23(53,5 \%)$ responderam plenamente ao tratamento exclusivo com a prednisona. Os $20(46,5 \%)$ necessitaram da introdução da azatioprina no protocolo de terapia. Portanto, dentre os 43 animais acompanhados, $37(86,0 \%)$ animais apresentaram controle satisfatório (avaliados pelos proprietários como melhora de 70 a $100 \%$ ) com as terapias ortodoxas ou heterodoxa. Em apenas um deles se obteve melhora de $40 \%$ (resposta insatisfatória) mesmo com a associação prednisona e azatioprina. Cinco $(11,6 \%)$ pacientes foram avaliados por somente período de até dois meses e quando então abandonaram o acompanhamento.

Em dois (10\%) animais tratados com a terapia heterodoxa observou-se trombocitopenia após introdução da azatioprina. No entanto, após a interrupção da medicação, houve retorno aos parâmetros de normalidade. Não foram observados quaisquer outros efeitos adversos.

\section{DISCUSSÃO}

Inexistiu predisposição sexual, tendo em vista que houve valores percentuais muito próximos quanto à ocorrência do PF entre machos e fêmeas, caninos $(44,2 \%$ eram machos e $55,8 \%$ eram fêmeas). Dados estes semelhantes àqueles observados por Ihrke et al (1985); Bensignor et al. 
(1998); Balda et al. (2002) e Mueller et al. (2006) respectivamente, nos EUA, França, Brasil (São Paulo) e Austrália.

Quanto à definição racial, 33 (76,7\%) animais tinhamna plenamente definida. As raças mais comumente acometidas foram: Cocker Spaniel, Dachshund, Poodle e Akita. A maioria dos autores tem citado evidente predisposição racial em cães de raça definida e de acordo com eles, as raças mais comumente envolvidas são: Akita, Chow Chow, Labrador, Pastor Alemão e Shar-Pei (Bensignor, 1998, Ihrke et al. 1985, Scott et al. 2001, Mueller et al. 2006).

Observou-se ampla variação de faixa etária de acometimento dos cães oscilando entre nove e 120 meses de vida. Tal dado, propiciado pelo proprietário, foi considerado como sendo o momento em que houvera o início do quadro lesional. Dos 43 animais com PF, 23 (53,5\%) dos animais estavam entre quatro a nove anos de idade. Quinze (35,0\%) estavam entre um e 3 anos de idade, dois $(4,6 \%)$ animais tinham mais que 9 anos e três $(6,7 \%)$ animais apresentavam menos de 1 ano no início do quadro lesional. A média de faixa etária foi de 4 anos e 2 meses, o que foi também constatado por Ihrke et al (1985). Recentemente pesquisadores estadunidenses relataram, dentre 91 cães penfigosos média etária superior a seis anos (Mueller et al. 2006).

Com relação ao quadro lesional, $100 \%$ dos animais penfigosos apresentaram crostas hemo-melicéricas e 40 (93\%) animais apresentaram lesões pustulares. Também foram evidenciadas pápulas em 32 animais $(76,7 \%)$, escamas em 29(67,4\%) animais, alopecia e eritema em 26 $(62,8 \%)$, hiperqueratose em $15(34,8 \%)$. A discromia, representada pela hiperpigmentação em 14 (32,5\%), sobrepujou os quadros hipopigmentares (4,6\%). A observação de lesões pustulares em $93 \%$ dos animais conflita com o que é referido na bibliografia. Segundo Balda et al. (2002) as lesões pustulares são observadas em $53 \%$ dos casos. As crostas hemáticas e melicéricas, lesões elementares classificadas no grupo das reparações teciduais, são relatadas pela maioria dos autores (Ihrke et al. 1985, Bensignor et al. 1998, Scott et al. 2001, Balda et al. 2002, Mueller et al. 2006) como sendo achado comumente observado nos quadros de PF, provavelmente pelo fato da epiderme dos cães ser mais adelgaçada em relação àquela da espécie humana as pústulas a serem bastante efêmeras, ou seja, são facilmente rompidas, provavelmente pelo fato do prurido ser detectado em mais da metade dos casos.

Topograficamente, as lesões foram identificadas mais freqüentemente nas regiões dorsal (41 animais, 95,3\%), ventral (40 animais, 93,0\%), axilar (36 animais, 83,7\%). Também, em desacordo com os demais autores, a ponte nasal não foi a localização inicial principal das lesões segundo os proprietários. Segundo Ihrke (1985) $51,2 \%$ dos animais, criados nos EUA, apresentam como localização lesional inicial a ponte nasal. Esta localização foi acometida em $19(44,2 \%)$ cães mas não como foco inicial. E a generalização lesional foi constatada em $90,7 \%$ dos pacientes penfigosos.
O protocolo de terapia empregado já há anos no SD do HOVET da FMVZ-USP é similar ao classicamente empregado em todas as latitudes. Inicia-se sempre com a prednisona per os na dose de $1-2 \mathrm{mg} / \mathrm{kg} /$ diariamente durante cerca de 45 dias. Aqueles (46,5\%) que não demonstraram melhora evidente neste período habitualmente são submetidos à terapia heterodoxa com a associação prednisona e azatioprina per os. Trinta e oito animais foram acompanhados por períodos que variaram de 3-50 meses. Cinco $(25,0 \%)$ animais deixaram de comparecer nos retornos aprazados e, portanto não foram considerados no cômputo final de eficácia. Dos 38 animais acompanhados, 37 animais apresentaram satisfatória melhora e apenas um animal ao final do período de segmento não mostrou melhora mesmo após instituição da terapia heterodoxa.

Em relação à comparação de eficácia do emprego da terapia ortodoxa à heterodoxa, observou-se que praticamente em $60 \%$ dos animais tão somente o esteróide mostrou-se efetivo e que $40 \%$ dos cães penfigosos necessitaram a esteróide-azatioprina. Estes percentis estão próximos àqueles relatados por Scott et al. (2001). Os autores norte-americanos consideraram que, aproximadamente, $50 \%$ dos animais não respondem à corticoideterapia isolada. Comparativamente aos dados compilados, englobando 30 animais, do mesmo Serviço (1986-2000) verificou-se que a magnitude dos casos coligidos, da ordem de 43 animais, propiciou a evidenciação de um incremento dos casos refratários à monoterapia esteroidal (46\%) relativamente ao primeiro dos trabalhos brasileiros enfocando a avaliação de eficácia (Balda et al. 2002). Pode-se ponderar que este evidente aumento de resposta dita "insatisfatória" se deve ao período mais longo de acompanhamento ou ao maior número de casos que vem sendo diagnosticados nos últimos anos no Serviço.

O número de casos atendidos mensalmente durante o período considerado no presente trabalho (2000-2005) foi de 0,7 . Comparando-se tais dados ao período de 19862000, onde tal relação no mesmo Serviço era de 0,23 casos mensais, pode-se considerar que houve uma meIhora em relação à eficácia do diagnóstico, já que em outros Serviços de Dermatologia observa-se média mensal constante também em torno de 0,4-0,6 casos por ano (Gomez et al. 2004, Mueller et al. 2006).

Em relação aos efeitos adversos sistêmicos, foram observados apenas dois $(4,6 \%)$ casos de trombocitopenia transitória em cães submetidos à terapia com azatioprina, o que indica a importância do acompanhamento desses animais com a execução de exames complementares periódicos, principalmente hemograma e contagem de plaquetas. Nenhum outro efeito colateral foi evidenciado, mas devem-se sempre levar em consideração outros possíveis efeitos colaterais como anemia, sangramento gastrintestinal e hepatotoxicidade, além da potencial ocorrência de quadros de pancreatite aguda relatados por outros autores (Mueller et al. 2004, Rosenkrantz, 2004). Assim, recomenda-se ainda, a realização dos exames de função hepática, renal, urina e principalmente de acom- 
panhamento clínico quinzenal durante a fase inicial de terapia e, no mínimo, semestral, após o estabelecimento das doses de manutenção, de todos os animais submetidos à terapia com imunossupressores.

\section{CONCLUSÕES}

Com relação aos 43 animais com diagnóstico confirmado de PF, pelo exame histopatológico, atendidos no Serviço de Dermatologia do HOVET da FMVZ-USP pode-se concluir que:

Não houve significante predisposição sexual, destarte, houve evidente predisposição racial. Dentre aquelas mais acometidas arrolam-se as raças Cocker Spaniel, Poodle, Dachshund e Akita. A faixa etária de maior incidência foi aquela dos 4-9 anos de idade, sendo que a média etária foi de 4 anos;

As três regiões mais acometidas foram a dorsal $(95,3 \%)$, abdominal ventral $(93,0 \%)$ e axilar $(88,7 \%)$. A generalização lesional foi observado em $91 \%$ dos casos em período de um a seis meses de evolução;

Os quatro tipos lesionais mais freqüentemente observados foram: crostas hemo-melicéricas $(100,0 \%)$, pústulas (76,7\%), pápulas $(76,7 \%)$ e escamas $(67,4 \%)$;

$40 \%$ dos animais não responderam de forma satisfatória à monoterapia com corticóides;

$97,4 \%$ dos animais acompanhados neste trabalho apresentaram flagrante melhora tanto com a terapia ortodoxa como com a heterodoxa;

Apenas 4,6\% dos animais submetidos à terapia associada à azatioprina apresentaram trombocitopenia como único efeito adverso e, portanto, pode-se concluir que esta associação é efetiva e segura nos tratamento de pacientes com PF.

\section{REFERÊNCIAS}

Balda A.C., Otsuka M., Michalany N.S. \& Larsson C.E. 2002. Pênfigo foliáceo em cães: levantamento retrospectivo de casos atendidos no período de novembro de 1989 a julho de 2000 e de resposta aos protocolos de terapia empregados no Hospital Veterinário da USP. Revta Bras. Ciênc. Vet. 9:97-101.
Bensignor E., Pin D. \& Carlotti D.N. 1998. Lê pemphigus foliacé dês carnivores domestiques. Ann. Méd. Vét. 142:5-13.

Gomez S.M., Morris D.O., Rosenbaum M.R. \& Goldschmidt M.H. 2004. Outcome and complications associated with treatment of pemphigus foliaceus in dogs: 43 cases (1994-2000). J. Am. Vet. Med. Assoc. 224:1312-1316.

Halliwell R.E.W. \& Goldshmidt M. 1977. Pemphigus foliaceus in the canine: a case report and discussion. J. Am. Vet. Med. Assoc. 180:4852. (Cit. Scott 1987)

Ihrke P.J., Stannard A.A., Ardans A.A. \& Griffin C.E. 1985. Pemphigus foliaceus in dogs: A review of 37 cases. J. Am. Vet. Med. Assoc. 186:59-66.

Larsson C.E., Lucas R., Otsuka M. \& Michalany N.S. 1998. Pênfigo foliáceo em cães: primeiras descrições em São Paulo, Brasil. Revta Clin. Vet. 13:28-32.

Mueller R.S., Krebs I., Power H.T. \& Fieseler K.V. 2006. Pemphigus foliaceus in 91 dogs. J. Am. Vet. Med. Assoc. 42:189-196.

Nascimento M.C.M.O., Lahm M.J.C. \& Franco S.R.V.S. 2000. Pênfigo foliáceo: relato de um caso não responsivo à corticoideterapia em um cão. Revta Bras. Ciênc. Vet. 7(Supl.):134.

Olivry T., Bergvall K.E. \& Atlee B.A. 2004. Prolonged remission after immunosuppressive therapy in six dogs with pemphigus foliaceus. Vet. Dermatol. 15:245-252.

Rosenkrantz W.S. 2004. Pemphigus: current therapy. Vet. Dermatol. 15:90-98.

Sampaio S.A.P. \& Rivitti E.A. 1998. Pênfigo foliáceo, p.231-238. In: Sampaio S.A.P. \& Rivitti E.A. (ed.), Dermatologia. 2a ed. Editora Artes Médicas, São Paulo. 1455p.

Scott D.W. 1987. Immune-mediated dermatoses in domestic animals: Ten years after. Part I. Comp. Cont. Educ. Small Anim. Pract. 9: 423.

Scott D.W., Manning T.O. \& Smith C.A. 1982. Observations on the immunopathology and therapy of canine pemphigus and pemphigoid. J. Am. Vet. Med. Assoc. 180:48-52.

Scott D.W., Miller Jr W.H. \& Griffin C.E. 2001. Immune-mediated skin disorders, p.667-779. In: (ed.), Small Animal Dermatology. 5th ed. W.B. Saunders, Philadelphia. 1528p.

Werner A.H. 1999. Recognizing and treating discoid lupus erythematous and pemphigus foliaceus in dog. Comp. Cont. Educ. Small Anim. Pract. 90:955-966.

White S.D. 2000. Treatment of autoimmune skin disease. 4th World Congr. Vet. Dermatology, San Francisco, California, p.173-174. 